\title{
Os desafios para o processo de democratização da escola pública
}

\author{
The challenges for the democratization process of the public school
}

\section{Los desafíos para el procedimiento de democratización de la escuela pública}

\author{
Daniela de Oliveira Pires ${ }^{1}$ \\ Universidade Federal do Paraná, Departamento de Planejamento e Administração Escolar, \\ Professora Adjunta

\section{Vera Maria Uidal Peroni ${ }^{2}$} \\ Universidade Federal do Rio Grande do Sul, Professora convidada
}

Resumo: $\bigcirc$ objetivo com este estudo foi analisar as consequências para a democratização da escola causadas pelo processo de transição política brasileira relativo ao final da Ditadura Civil-Militar (1964-1985) até a promulgação da Constituição Federal de 1988. Fernandes (2005) afirma que as transições políticas brasileiras se caracterizam por meio dos "pactos pelo alto", o que acaba por promover a manutenção do controle das elites dirigentes e, no caso específico do contexto ora compreendido, a permanência da influência política das forças militares, após o final do regime de exceção. A metodologia utilizada no desenvolvimento do estudo foi a análise bibliográfica e normativa. Com base no recorte histórico-normativo, foram analisados os primeiros Atos Institucionais, medidas arbitrárias impostas pelo poder executivo e que caracterizaram uma das manifestações de poder e autoridade. São apresentados aspectos referentes ao processo de redemocratização do País, com destaque para a aprovação da Lei de Anistia (Lei n. 6683/79) e sobre o papel das organizações e os fóruns em defesa da democracia e da escola pública, bem como sobre os desafios na efetivação da democratização da escola. Como encaminhamentos finais, considerando que a transição democrática é tida como incompleta e inacabada, acrescido do processo de reconfiguração do papel do Estado, a partir dos anos 1990, por meio do repasse da responsabilidade na promoção do direito

Doutora e Mestre em Educação pelo Programa de Pós-Graduação em Educação da Universidade Federal do Rio Grande do Sul (PPGEDU/UFRGS).

2 Doutora em História e Filosofia da Educação pela Pontifícia Universidade Católica de São Paulo (PUC/SP); Mestre em Educação pela Universidade Federal de Mato Grosso do Sul. 
à educação para as entidades privadas, com primazia da gestão gerencial, em contraposição à gestão democrática, tem-se, com isso, um afastamento gradativo dos mecanismos de democratização da escola, consagrados pela Carta Política de 1988.

Palavras-chave: Estado brasileiro. Ditadura Civil-Militar. Transição política. Processo de redemocratização. Gestão democrática da escola.

Abstract: The purpose of the study is to analyze the consequences for the democratization of the school through the Brazilian political transition process, related to the end of the Civil-Military Dictatorship (1964-1985) until the enactment of the Federal Constitution of 1988. Fernandes (2005) argues that Brazilian political transitions are characterized by "pactos por alto", which ultimately promotes the maintenance of the control of the ruling elites, and in the specific case, the context here understood, the permanence of the political influence of the military forces, after the end of the regime of exception. The methodology used in the development of the study was the bibliographical and normative analysis. Based on the historical-normative clipping, the first Institutional Acts, arbitrary measures imposed by the executive power and that characterized one of the manifestations of power and authority, were analyzed. There are aspects related to the country's re-democratization process, with emphasis on the approval of the Amnesty Law (Law n. 6.683/79) and on the role of organizations and forums in defense of democracy and the public school, as well as on the the democratization of the school. As final referrals, considering that the democratic transition is seen as incomplete and unfinished, and the process of reconfiguration of the state's role since the 1990s, through the transfer of responsibility in promoting the right to education for private The primacy of managerial management, as opposed to democratic management, leads to a gradual departure from the democratization mechanisms of the school, enshrined in the 1988 Political Charter.

Keywords: Brazilian State. Civil-Military Dictatorship. Political transition. Redemocratization process. Democratic management of the school.

Resumen: El objetivo del estudio es analizar, a través del proceso de transición política brasileña, relativo al final de la Dictadura Civil-Militar (1964-1985) hasta la promulgación de la Constitución Federal de 1988, las consecuencias para la democratización de la escuela. (En el caso específico, del contexto ya 
comprendido, la permanencia de las mismas, en el caso concreto, del contexto actual, de la influencia política de las fuerzas militares, tras el final del régimen de excepción. La metodología utilizada en el desarrollo del estudio fue el análisis bibliográfico y normativo. Con base en el recorte histórico-normativo, se analizaron los primeros Actos Institucionales, medidas arbitrarias impuestas por el poder ejecutivo y que caracterizaron una de las manifestaciones de poder y autoridad. Se presentan aspectos referentes al proceso de redemocratización del país, con destaque para la aprobación de la Ley de Amnistía (Ley n. 6683/79) y sobre el papel de las organizaciones y los foros en defensa de la democracia y la escuela pública, así como, desafíos en la efectivización de la democratización de la escuela. Como encaminamientos finales, considerando que la transición democrática se considera incompleta e inacabada, más el proceso de reconfiguración del papel del Estado, a partir de los años 1990, a través del traspaso de la responsabilidad en la promoción del derecho a la educación para las entidades privadas, la primacía de la gestión gerencial, en contraposición, la gestión democrática, se tiene con ello un alejamiento gradual de los mecanismos de democratización de la escuela, consagrados por la Carta Política de 1988.

Palabras clave: Estado brasileño. Dictadura Civil-Militar. Transición política. Proceso de redemocratización. Gestión democrática de la escuela.

\section{INTRODUÇÃO}

Objetivo no artigo é demonstrar, com base no processo de transição da Ditadura Civil-Militar (1964-1985) para o Estado Democrático de Direito, por meio da promulgação da Constituição Federal de 1988, quais são os desafios atuais para a consolidação da democratização da escola pública. Para efeitos dessa análise, democratização aqui é entendida como a materialização de direitos em políticas coletivamente construídas na autocrítica da prática social (PERONI, 2016). Sobre os 21 anos de duração do Estado de exceção, especificamente no campo educacional, o texto se propõe a problematizar o estímulo à ação privatizante da educação, com o fortalecimento dos grupos privados. É importante destacar que, ao final do período de exceção, especialmente a partir 
dos anos 1990, tem-se a propagação do Neoliberalismo e da Terceira Via, com suas respectivas estratégias, quais sejam as privatizações e o Terceiro Setor, o que acaba por evidenciar os desafios para a implementação da gestão democrática, bem como o fortalecimento da autonomia das escolas públicas.

estudo, portanto, foi estruturado na perspectiva desse período histórico contraditório e singular. Contraditório, pois uma vez que não rompemos, até os dias de hoje, com o passado ditatorial, na medida em que sequer houve responsabilização pelas torturas, mortes e desaparecimentos políticos por parte dos agentes do Estado brasileiro; tem-se, assim, um processo de transição incompleta e inacabada, sendo que uma das principais consequências é a fragilidade das estruturas democráticas, em todas as esferas da sociedade, incluindo as escolas públicas.

Para tanto, na primeira parte, é abordado o contexto da Ditadura CivilMilitar (1964-1985) até o processo de abertura democrática nos anos 1980, com o propósito de demonstrar as difíceis consequências que um processo de transição política ainda em andamento acaba por promover na consolidação da gestão democrática nas escolas públicas.

Na segunda parte, é mencionado o processo de redemocratização dos anos 1980, com destaque para a organização do Movimento em Defesa da Educação Pública e os embates educacionais na Assembleia Constituinte de 1987. o que definiu, na Carta Política de 1988, ações do setor público e do privado (com e sem fins lucrativos), assim como do público não estatal. A metodologia se baseou na análise bibliográfica e normativa, dialogando com autores como Fernandes (2005), Peroni (2003), Germano (1994) e Vieira (1992, 2014).

$\mathrm{Na}$ última parte do estudo, apresentamos dois processos que entraram em contradição com a política de valorização da escola pública e seus mecanismos de gestão democrática, dentre eles a autonomia, defendida pelos movimentos sociais que se estruturavam nos anos 1980, o Neoliberalismo e a Terceira Via. Esses movimentos culminaram por impulsionar as redefinições do papel do Estado, apregoadas pelos seus teóricos, defensores do chamado Estado Mínimo, que se materializa, segundo Peroni (2003, p. 32), "[...] mínimo para as políticas sociais e máximo para o capital", institucionalizando, assim, a 
desobrigação do poder estatal e o advento das parcerias público-privadas na oferta da educação, com implicações para a democratização da escola.

Ao final, nas Considerações Finais, sustenta-se o distanciamento existente entre a promoção do direito à educação apregoado pelos aparatos legais e a concretização da gestão da escola em uma perspectiva democrática, quando se percebe que as ações governamentais são pela sua mercantilização e privatização.

\section{ASPECTOS DO ESTADO CIUIL-MILITAR E ESTÍMULO AO EMPRESARIADO DA EDUCAÇÃO: O ROMPIMENTO COM O IDEÁRIO DEMOCRÁTICO}

No dia 01 de abril de 1964, um Golpe Civil-Militar afastou do poder o então Presidente João Goulart, que havia sido eleito democraticamente, instaurando-se no Brasil um regime de exceção que se estendeu por mais de duas décadas, contando com amplo apoio de vários setores da classe dominante brasileira: os militares, os setores da política nacional, o empresariado, os latifundiários, a grande mídia, além do apoio decisivo dos Estados Unidos, que financiaram todas as ditaduras que ocorreram nesse período nos países da América Latina. Germano (1994, p. 21) sintetiza o perfil do Estado Militar:

Estado Militar é assim encarado em sua historicidade, enquanto expressão de uma fase do desenvolvimento do capitalismo no Brasil, que ocorre sob a égide dos monopólios e que expressa, sobretudo, os interesses dos conglomerados internacionais, de grandes grupos econômicos nacionais e das empresas estatais, formando um bloco cuja direção é recrutada nas Forças Armadas e que conta com o decisivo apoio dos setores tecnocráticos.

O estágio do desenvolvimento capitalista brasileiro durante o Governo Civil- Militar se caracterizou pela intervenção do Estado na economia, favorecendo a burguesia industrial e o capital financeiro internacional. 
$\bigcirc$ Governo Militar passa a investir nas áreas de construções de estradas, energia elétrica e telecomunicações, por intermédio do "apoio" financeiro das instituições estrangeiras. Durante esse período, o investimento econômico ocorreu em duas frentes, financiamento de empresas estatais de setores estratégicos, como energia e transporte, estímulo da entrada do capital internacional e investimento nos órgãos da repressão política (PIRES, 2015).

Conforme mencionamos anteriormente, o Governo Militar foi apoiado por amplos setores da sociedade brasileira e que passam a exercer influência direta na condução dos negócios públicos, privatizando as instâncias de decisões governamentais. $\bigcirc$ Estado passa a ser conduzido segundo fatores privatistas, “[...] empreiteiras, bancos, conglomerados industriais - que, num conluio com militares, tecnoburocratas e altos escalões governamentais transformaram o aparelho estatal numa máquina de corrupção e de fraude a serviço dos seus interesses." (GERMANO, 1994, p. 86). Percebe-se que a União controlava diretamente todas as instâncias de poder, a esfera pública e a esfera privada, os meios de comunicação, as organizações sociais, os sindicatos, as entidades de classe, em que pese não havia um controle acerca das ações estatais, que agia livremente, com ausência de controle social. $\bigcirc$ beneficiamento das elites em detrimento da maioria da população pode ser verificado também em relação aos direitos sociais, pois passa a figurar o monopólio empresarial no âmbito da sua promoção, conforme podemos averiguar a partir da contribuição de Germano (1994, p. 93):

[...] as verbas para a saúde pública foram minguando ao longo do tempo e, no entanto, o Estado transferia substanciais recursos para o setor privado de saúde. Assim, 1981, 72\% do total dos recursos destinados à assistência médica e previdência social (em parte oriundo dos assalariados) foram parar nas mãos dos empresários da saúde. Na área educacional, apesar das reformas, o Estado se descomprometeu gradativamente em financiar a educação pública; os recursos estavam comprometidos com o capital privado, repassando, ainda assim, verbas para as escolas particulares. 
A educação nesse período deveria se tornar uma atividade essencialmente lucrativa, ou seja, a prioridade era a privatização do ensino. Para tanto, o repasse de recursos para a educação pública era visto como um prejuízo, pois não atendia às expectativas do mercado, no entanto o investimento nos estabelecimentos de ensino privado legitimava a mercantilização da educação e impulsionava o aumento dos ganhos dos aliados políticos do Golpe Civil-Militar. Tal perspectiva estreita da educação, orientada segundo os preceitos economicistas, acabou por impulsionar a hegemonia do setor privado na educação, estabelecendo-se em todos os níveis de ensino. Assim, a educação inserida no processo de correlação de forças sociais do período foi promovida segundo a lógica privada, com o apoio político do Estado civilmilitar (PIRES, 2015).

É importante frisar que os militares viam na educação, além do seu caráter lucrativo, também um importante instrumento de controle ideológico das massas. Nesse aspecto não se reconhece a desobrigação do Estado, ao contrário, ele passa a assumir as atividades voltadas à repressão e à perseguição dos sujeitos da educação que questionavam as diretrizes da esfera do poder central. Para tanto, em determinadas situações era estratégico que o Governo atuasse de maneira direta e centralizadora. Nesse período, o Estado passa a intervir diretamente na economia, ocorrendo, com isso, a institucionalização da sua militarização. Outra manifestação do centralismo e do autoritarismo político foi o advento dos Atos Institucionais, que eram normas e decretos outorgados pelo poder executivo, em evidente desrespeito à teoria da separação dos poderes, pois o executivo passa a legislar em dissonância aos preceitos constitucionais.

No Ato Institucional $n^{\circ}$ l, "o Supremo Comando Revolucionário passava a ter atributos de Poder Constituinte. Se o Ato Institucional $\mathrm{n}^{\circ} \mathrm{l}$ conservava a Constituição de 1946 e as Constituições Estaduais, com suas emendas, de outra parte instituía pela primeira vez a eleição indireta". (VIEIRA, 2014, p. 32-33).

$\bigcirc$ que se constata é que tais normas foram as primeiras ações com vistas à legitimação do rompimento da ordem constitucional, sendo que ao 
total foram editados 17 atos, que possibilitaram ao Governo amplos poderes para alterar a então vigente Carta Política de 1946, como no caso da alteração na forma das eleições brasileiras. Como exemplo, o ato institucional n. 2, que determinava as cassações de mandatos e a suspensão de direitos políticos, mas permitia o funcionamento do congresso, em evidente contradição.

Já o ato institucional n. 4 veio dar legitimidade à outorga da Constituição de 1967, que continha no seu texto a imposição dos valores do "Movimento de 1964", e, portanto, o seu texto evidenciava absoluta incompatibilidade com o texto da Carta de 1946. Ao analisar o texto, percebe-se a centralização da União, pois os primeiros artigos tratam fundamentalmente das competências da União, inclusive com previsão de interferir nos estados para "pôr termo a grave perturbação da ordem ou ameaça de sua irrupção" (art. 10, III), passando a vigorar a Lei de Segurança Nacional, na qual é reservado um capítulo próprio, que corresponde aos arts. 89 a 91. A manutenção da "ordem" e a preservação da "segurança nacional" foram os argumentos utilizados para o rompimento do pacto federativo, do respeito à autonomia dos entes federados e das liberdades individuais e coletivas, em nome da chamada "unidade nacional", como é possível constatar no artigo a seguir:

Art. 168 - A educação é direito de todos e será dada no lar e na escola; assegurada a igualdade de oportunidade, deve inspirar-se no princípio da unidade nacional e nos ideais de liberdade e de solidariedade humana. [...] $\S 2^{\circ}$ - Respeitadas as disposições legais, o ensino é livre à Iniciativa particular, a qual merecerá o amparo técnico e financeiro dos Poderes Públicos, inclusive bolsas de estudo. (BRASIL, 1967).

A Carta de 1967, além de significar uma usurpação dos valores democráticos, que particularmente sobre a educação retira a previsão da igualdade de oportunidade, evidenciava que as oportunidades seriam proporcionadas àqueles que pudessem arcar com os custos da sua promoção. Posteriormente, a publicação do ato institucional n. 5 é considerada o "golpe dentro do Golpe", pois se aprofundaram as perseguições e a tortura àqueles que legitimamente utilizavam o direito de resistir às atrocidades cometidas pelo Regime. 
Especificamente sobre a promoção educacional, foi contratada nos primeiros anos do Governo Civil-Militar uma assessoria norte-americana para auxiliar na construção do "novo paradigma educacional". Ao final do trabalho, a empresa contratada, a Usaid, produziu um relatório no qual sugeria “[...] a importância de racionalizar a universidade, organizando-a em moldes empresariais, privilegiando, assim, a questão da privatização do ensino em todas as instâncias." (GERMANO, 1994, p. 117). As recomendações da empresa norte-americana foram bem recebidas pelo Governo brasileiro, haja vista que a educação já era reconhecida pelos militares como uma questão de mercado.

Imposição da ordem, controle pedagógico e ideológico e redução de custos operacionais podem sintetizar as recomendações estadunidenses para a educação brasileira. Corroborando a lógica privatista, observa-se que havia um esforço tanto do Estado quanto dos grupos sociais hegemônicos para privatizar a educação pública. Prova disso foi a organização de um Fórum em 1968, no Rio de Janeiro, intitulado A Educação que nos convém, demonstrando que "extrapolando a esfera estrita do Estado, a questão educacional passa a preocupar também setores das classes dominantes." (GERMANO, 1994, p. 129). A preocupação das elites não surge apenas em 1968, mas a partir desse período, com o acirramento das perseguições políticas, sendo a educação reconhecida como um meio de "controlar/monitorar" os chamados "inimigos do Estado", e havendo na organização do Estado representantes da elite nacional, composta por intelectuais, empresários, burocratas e militares, que viam na educação uma forma de ampliar suas vantagens econômicas, em suma, tornase uma questão estratégica para a manutenção do status quo a condução da política educacional (PIRES, 2015).

Essa tese foi incorporada ao texto da Emenda Constitucional n. 1, de 17 de outubro de 1969, reconhecida como uma nova Carta Política, pois reeditou o novo texto da Constituição Federal de 1967 ao tratar do ensino médio, e "[...] prevê a substituição gradativa do 'regime de gratuidade' não somente no tocante ao ensino superior, mas também no que diz respeito ao ensino médio, mediante a adoção do sistema de bolsas de estudo restituíveis. " (GERMANO, 1994, p. 144). Isso significa que o Estado, além de se desobrigar com a educação, passou a financiar as instituições privadas. Em relação ao 
ensino superior, podemos afirmar a elitização desse nível de ensino com a gradativa desobrigação do Estado e o estímulo tanto à criação quanto ao financiamento público das entidades privadas, que passam a liderar o número de matrículas nesse nível de ensino.

É possível concluir até o momento que esse foi o período da história brasileira em que houve maior impulso à lógica privatista na educação, inclusive em períodos de maior avanço democrático, como ocorreu na Constituição de 1934, que declarava o dever do Estado em relação à educação e favorecia os estabelecimentos de ensino privado com isenções fiscais, estimulando de forma ampla o financiamento público das instituições de ensino privadas. Entretanto, é a partir da instauração do processo ditatorial no País que ocorre um maior estímulo ao empresariado da educação, em que o seu propósito passa a ser essencialmente a lucratividade (PIRES, 2015).

$\bigcirc$ Estado civil-militar legitima esse novo paradigma educacional amparado no Texto Constitucional e nas legislações infraconstitucionais. primeiro retrocesso em relação à educação pública ocorre com a outorga da Carta Política de 1967, que, contrariando uma tendência constitucional que teve início na Constituição de 1934 e que havia sido retomada na Carta Política de 1946, retirou a determinação de fixar percentuais mínimos a serem empregados na educação pelos entes federados, fazendo com que o financiamento na educação pública diminuísse consideravelmente. Outra previsão constitucional determinava a possibilidade de concessão de bolsas de estudos para as instituições privadas, sob a alegação de que o poder público deveria prestar o amparo técnico e financeiro a tais entidades.

Com isso, o Regime Ditatorial não somente diminuiu o repasse para o ensino público como fortaleceu a iniciativa privada. Nesse sentido, percebemos que a relação público-privada na educação ocorre de duas maneiras: indiretamente, conforme já mencionamos, quando o Estado repassa recursos para fins de "auxílio técnico e financeiro", o que significa que a verba pública passa a ser utilizada na melhoria da estrutura física das escolas, na formação dos profissionais da educação, e diretamente, por meio da compra de bolsas de estudo. 
$\bigcirc$ último presidente militar, o General João Baptista Figueiredo, assume o Governo em 15 de março de 1979 com a promessa de iniciar o processo de democratização do País. Em termos mundiais, nesse momento estava em curso mais uma crise do capitalismo, desencadeada a partir de 1973, em razão do déficit da oferta do petróleo, o que provocou o aumento das taxas de juros internacionais. Esse contexto de crise do capitalismo é aprofundado na próxima subseção, pois ocasionou a reforma do Estado brasileiro, havendo consequências para a consecução dos direitos sociais, dentre eles a educação e a reforma do Estado brasileiro. Em razão da política econômica interna, acrescida da crise do capitalismo mundial, essas duas crises fizeram com que, em 1982, o País tivesse que recorrer mais uma vez ao "auxílio" do Fundo Monetário Internacional (FMI). A dívida externa do Brasil atingiu o patamar de 100 bilhões de dólares. A partir dos anos 1980, com o aprofundamento da crise econômica e social, a Ditadura Civil-Militar entra em declínio, corroborando, para esse contexto, a organização de vários setores da sociedade brasileira, dos movimentos grevistas, de trabalhadores rurais e urbanos que exigiam uma série de direitos trabalhistas e o retorno imediato da democracia (PIRES, 2015).

$\bigcirc$ resultado da política educacional privatizante produzida durante os anos do Estado de exceção, com a desobrigação do Estado no campo educacional, culmina na crise do ensino público e no favorecimento do empresariado da educação. Na segunda parte do estudo são apresentados os fatores que levaram ao final do período de exceção e a condução da política educacional brasileira no período de redemocratização, assim como a tensão entre os pressupostos da gestão democrática e a gerencial na escola e na educação. Na próxima parte, são apresentados aspectos da transição democrática, com destaque para a aprovação da Lei de Anistia, no final dos anos 1980, e da propagação do Neoliberalismo, a partir dos anos 1990, e as consequências desses processos históricos para a democratização da escola. 


\title{
3 OS ANOS 1980 E 1990: A DEFESA DA DEMOCRATIZAÇÃO DA ESCOLA PÚBLICA
}

Os anos 1980 foram marcados pelo aprofundamento da crise econômica em escala internacional e nacional e, também, pelo processo de redemocratização, que ocorre de forma lenta e gradual no País, que teve sua primeira manifestação com a aprovação da Lei n. 6.683, de 17 de agosto de 1979, conhecida como a Lei da Anistia. No seu art. $1^{\circ}$ expressa o seu objetivo:

\begin{abstract}
Art. $1^{\circ}$ É concedida anistia a todos quantos, no período compreendido entre 02 de setembro de 1961 e 15 de agosto de 1979, cometeram crimes políticos ou conexo com estes, crimes eleitorais, aos que tiveram seus direitos políticos suspensos e aos servidores da Administração Direta e Indireta, de fundações vinculadas ao poder público, aos Servidores dos Poderes Legislativo e Judiciário, aos Militares e aos dirigentes e representantes sindicais, punidos com fundamento em Atos Institucionais e Complementares.
\end{abstract}

É exatamente esse dispositivo que contém a questão mais polêmica da Lei da Anistia, pois ela previa anistia tanto para os torturadores quanto para os torturados, sob a alegação do advento dos chamados "crimes conexos" e "crimes de sangue, permitindo a chamada "autoanistia". Com a aprovação dessa legislação, considerada como a "legislação possível", considerando que na época não havia sequer oposição no Congresso Nacional, mas uma oposição consentida pelo próprio Regime, foi possível o regresso de um grande número de exilados políticos e permitiu-se o início do processo de abertura política no País (PIRES, 2015).

Em termos políticos, Fernandes (2005) afirma que houve a manutenção e o controle da hegemonia das forças militares. Houve, portanto, um retorno ao regime democrático, mas com a permanência da influência militar em todas as esferas de poder.

É nesse contexto, a partir da aprovação da Lei n. 6.683/79, com a retomada do processo de redemocratização, que essa parte da reflexão tem 
início. Nos primeiros anos de 1980, é evidente o esgotamento do Regime CivilMilitar brasileiro, em razão dos questionamentos da sociedade e por parte dos organismos internacionais sobre as graves violações aos direitos humanos e a profunda crise econômica já em andamento. Existem dois processos que influenciaram a definição da política educacional nesse período histórico e que entraram em contradição com a lógica de valorização da educação pública e democrática, defendida pelos movimentos sociais que se estruturavam nos 1980. quais sejam, a crise do capitalismo e a propagação do Neoliberalismo. ${ }^{3}$ A crise do capitalismo tem início nos anos 1970, definindo para as décadas posteriores a predominância mundial da orientação neoliberal, que se contrapõe ao modelo de Estado de bem-estar social ou Welfare State, difundido na Europa, pós $2^{a}$ Guerra Mundial (1939-1945), que impôs aos estados a realização de reformas que ocasionaram mudanças no atendimento das políticas públicas sociais, não somente da educação, como dos demais direitos sociais (saúde, assistência social, segurança pública) (PIRES, 2015).

Nesse aspecto reside uma contradição importante como forma de compreender os limites e possibilidades da democratização da escola pública, pois, enquanto o Brasil e os demais países latino-americanos lutavam pelo fim das ditaduras civil-militares, pela defesa da escola pública, da gestão democrática e de uma maior participação do Governo na sua promoção, mundialmente está havendo um processo inverso, uma vez que, a partir do avanço do Neoliberalismo, tem-se o estímulo à privatização dos direitos sociais, à não intervenção do Estado na economia e à maximização da influência dos organismos financeiros mundiais. É nesse processo histórico de avanços (internos) e retrocessos (internacionais) que a educação pública e democrática

\footnotetext{
$3 \bigcirc$ pensamento neoliberal desdobrou-se, no pós-guerra, em algumas linhas ou variantes. Três delas são mais claramente definidas, embora uma quarta, a dos "anarco-capitalistas" ou minimarquistas, como Robert Nozick, devesse ser lembrada. Mas as três principais são, pela ordem das "datas de nascimento": escola austríaca, liderada por Friedrich August von Hayek, o patrono de todo o pensamento neoliberal contemporâneo; escola de Chicago, personificada em T. W. Schultz e Gari Becker (ligada à teoria do capital humano), e principalmente Milton Friedman (1912-), o grande homem de mídia dessa escola, e a escola de Virgínia ou public choice, capitaneada por James M. Buchanan (1919-). O grande nome da corrente neoliberal é, sem dúvida, Friedrich August von Hayek (1899-1922). Herdeiro da chamada escola austríaca de economia, o pensamento de Hayek é um descendente das reflexões de Carl Menger (1840-1921) e da posição ardorosamente antiestatista e antissocialista de Ludwig von Mises (MORAES, 2001, p. 42-43).
} 
volta ao debate nacional. Uma das manifestações sociais desse período foi o Fórum Nacional em Defesa da Escola Pública (FNDEP). O principal objetivo do FNDEP era a organização de um processo constituinte que levasse à discussão de uma nova constituição para o País. Segundo Peroni (2003, p. 75): "O fórum foi oficialmente lançado em Brasília, em 9 de abril de 1987, na Campanha Nacional em Defesa da Escola Pública e Gratuita, tendo sido denominado, inicialmente, de Fórum da Educação na Constituinte em Defesa do Ensino Público e Gratuito."

Dentre as suas reivindicações, duas questões se destacavam, a luta contra a Ditadura e a defesa da educação pública. As demandas contidas nas pautas dos movimentos sociais expressavam o repúdio da sociedade com a forma como a política educacional havia sido conduzida pelo Governo Militar, caracterizada pelo seu viés privatizante e de recusa ao caráter social e coletivo do ensino. A resposta dos setores privados foi imediata, reafirmando a correlação de forças sociais entre o público e o privado durante o processo constituinte de 1987.

Durante o processo constituinte, as principais forças que
se opuseram ao FNDEP, segundo Gohn (1994), foram
as escolas particulares privadas por meio da Federação
Nacional de Estabelecimentos de Ensino (Fenem) e o
setor privado confessional, por intermédio da Associação
Brasileira de Escolas Superiores Católicas (Abesc) e da
Associação da Educação Católica. (PERONI, 2003, p. 76).

Durante o processo constituinte de 1987-1988, o fortalecimento da bipolaridade entre os defensores da escola pública e os setores privados evidencia algumas questões candentes, como o ensino religioso nas escolas públicas, a gestão democrática, questões que atravessaram $\circ$ período republicano, e o repasse de verbas públicas para escolas particulares, que se fortaleceu fundamentalmente a partir da Lei de Diretrizes e Bases da Educação Nacional (LDB) de 1961 (OLIVEIRA, 2005).

Os defensores da escola pública estatal, que propunham a aplicação exclusiva das verbas públicas nas escolas 
públicas; os setores confessionais, notadamente católicos, mas também metodistas e presbiterianos, que defendiam uma diferenciação entre as escolas públicas, classificandoas entre estatais e não-estatais e o setor privado-empresarial que, apesar de não se opor ao repasse de verbas públicas (muito pelo contrário), centrava suas demandas na nãoingerência do Poder Público na regulação as anuidades escolares. (OLIVEIRA, 2005, p. 156).

Com a ampliação das noções de público e privado quanto à promoção da educação, tem-se uma fusão dos conceitos, uma verdadeira e autêntica confusão conceitual, pois passamos a contar com as chamadas instituições "não estatais". As escolas públicas não estatais rompem com as noções de público e privado, sendo definidas como "um conjunto de iniciativas particulares com um sentido público." (FERNANDES, 2005, p. 127)

Nesse ponto, podemos afirmar que, no debate constituinte que definiu as diretrizes educacionais que seriam incorporadas no texto final da Constituição Federal de 1988, duas tendências se consagraram: o reconhecimento legal das instituições privadas com fins lucrativos e a lógica do público não estatal, que impulsionou a relação das entidades do Terceiro Setor com o setor público na promoção dos direitos sociais, pois apenas 10 anos após a promulgação da Constituição de 1988 foram editadas, respectivamente, a Lei n. 9.637/98, que trata das Organizações Sociais (OS), e a Lei n. 9.790/99, das Organizações da Sociedade Civil de Interesse Público (OSCIPS), que fortalecem a tendência já difundida mundialmente sobre a sociedade civil atuar diretamente na promoção dos direitos sociais.

Essas legislações possuem relação com a reforma promovida no Estado brasileiro a partir dos anos 1990 e a propagação da Terceira Via, que veremos na próxima seção. Esse contexto é de aprofundamento da relação entre o público e o privado, no campo de atuação das políticas sociais, uma vez que tal obrigação deixa de ser exclusiva do Estado, pois é descentralizada para os entes privados. Tais reformas foram justificadas em razão da crise do Estado de bem-estar social. Sobre esse diagnóstico, já nos posicionamos no sentido de que ocorreu uma crise no sistema capitalista, sendo a reforma dos Estados sua consequência direta. Acrescido a isso, em relação ao contexto brasileiro, o País 
não vivenciou o processo do Welfare State (PIRES, 2009). Podemos afirmar que, no Brasil, vivenciamos a experiência de um Estado desenvolvimentista.

Um número significativo de países europeus possibilitaram, não sem luta, à classe trabalhadora uma efetiva melhoria de vida e uma garantia de fundo público de amplos direitos sociais como: saúde, habitação, educação, emprego e seguro-desemprego etc. Efetivou-se, de outra parte, um processo concreto de ganhos reais de produtividade por parte da classe trabalhadora. Esta realidade tem sido bastante diversa nos países latino-americanos, de colonialismo e subserviência aos centros hegemônicos do capitalismo internacional. Entre nós, como lembra Galeano, conhecemos o Estado de mal-estar social. (BIANCHETTI, 1999, p. 10).

De acordo com o entendimento de Vieira (1992), no Brasil não houve a materialização de um modelo de bem-estar social, na sua acepção, mas apenas um tímido avanço no campo de algumas garantias e da legitimação de alguns direitos considerados básicos, dentre eles a saúde e a educação. Os primeiros sinais da crise do Estado Intervencionista iniciaram na década de 1970, diante das "contradições inerentes ao capitalismo" (HARVEY, 1989, p. 135), que se materializavam, ainda segundo o autor, pela "[...] rigidez dos compromissos do estado, rigidez nos mercados [...] e a flexível política monetária, na capacidade de imprimir moeda em qualquer montante que parecesse necessário para manter a economia estável" (HARVEY, 1989, p. 136), pois as necessidades do sistema do capital sempre devem prevalecer em relação ao atendimento das necessidades básicas da população.

Diante desse cenário, o Neoliberalismo predominou na condição de orientação econômica e social, fazendo com que o Estado passasse por um processo de reconfiguração do seu próprio papel, em todas as suas esferas e em relação às suas próprias determinações, de caráter social, econômico e político.

Essa ideologia privatista ganhou força com o esgotamento do regime militar e se somou à ideia e práticas arraigadas em nosso país. Os grupos econômicos (privados) passaram a acusar o Estado pela crise dos anos 80, desde a retomada 
do processo inflacionário até a manutenção de uma grande, onerosa e desnecessária burocracia, passando pela crescente dívida interna, atribuída à necessidade de empréstimos a juros cada vez mais altos, alimentando uma especulação financeira sem precedentes. Omitiam é claro, que o déficit público também resultava do favorecimento ao setor privado mediante a inoperância da máquina fiscal, as isenções tributárias, as transferências diretas e indiretas (como as bolsas de estudo para as escolas privadas), os empréstimos a juros negativos e os subsídios a fundo perdidos. (CUNHA, 2009, p. 13-14).

autor situa a forma como essa orientação política passa a se legitimar no País quando os grupos privados, os maiores beneficiados pela política econômica durante os anos da Ditadura, que os financiou de maneira irrestrita, passam a criticá-la, afirmando que o Estado é o culpado pela crise. Podemos constatar que o mercado se torna o agente regulador da vida em sociedade, e não mais o Estado, sob o argumento de que a esfera pública não é eficiente. Para Sanfelice (2005, p. 62):

[...] $\bigcirc$ Estado passa a ser foquista nas políticas sociais e vai jogando tudo para o mercado. O Estado faz política de foco. São políticas de gerenciamento das tensões maiores ou aquelas que exigem investimentos que o setor privado não quer fazer. [...] A mercantilização dos direitos sociais não politiza a sociedade civil.

Assim, a prestação das necessidades básicas da população, o que equivale a dizer a promoção das políticas públicas sociais deve ser executada seguindo uma lógica que favoreça as relações de mercado, tendo como estratégia a privatização das instituições públicas, passando a responsabilização para o mercado. No Brasil, a experiência neoliberal se consolidou com a eleição para a presidência de Fernando Collor de Melo em 1990, quando mundialmente está se desenvolvendo uma nova orientação política, a Terceira Via, que possui como estratégia não as privatizações, mas o Terceiro Setor e o fortalecimento da gestão gerencial em detrimento da gestão democrática nos processos escolares (PIRES, 2009). 
A Constituição Federal de 1988 consagrou em seu texto, sob a correlação de forças daquele momento, tanto os valores e princípios da gestão democrática quanto os interesses relacionados à educação privada, ou, ainda, dos "setores confessionais" e do "setor empresarial", que já foi mencionado na seção anterior. A educação brasileira foi bastante influenciada, a partir da década de 1990, pelas reformas empreendidas pelo Estado brasileiro, principalmente durante o primeiro mandato do Presidente Fernando Henrique Cardoso (1994-1998). Essas reformas receberam uma forte influência dos organismos internacionais, uma vez que os governos estavam economicamente atrelados a esses organismos, entre os quais o Fundo Monetário Internacional (FMI), o Banco Mundial (BM), a Organização das Nações Unidas para a Educação, a Ciência e a Cultura (Unesco), a Organização Internacional do Trabalho (OIT), a Organização Mundial do Comércio (OMC) e a Comissão Econômica para América Latina e Caribe (CEPAL) (PIRES, 2009).

A reforma educacional em curso no Brasil colocava a educação como um eixo entre a reforma e a produtividade e objetivava assegurá-la para todos, desde que fosse eficiente. Dessa maneira, ocorreram mudanças de ordem prática no sistema educativo, como maior flexibilidade, descentralização e competitividade, o que acarretava em marcos conceituais educativos e transformava o Estado num mero fiscalizador das políticas educacionais. Como consequência, as escolas e os processos educacionais se viram diante de uma lógica que não privilegiava o ideário democrático do ensino, mas a lógica de mercado e da competição, ou seja, a lógica gerencial.

Nesse cenário, o Governo federal promulgou, em 1995, o Plano Diretor de Reforma do Aparelho do Estado (PDRAE), que possuía, entre as suas premissas principais, o estímulo à realização das parcerias entre a esfera pública e a privada na promoção dos direitos sociais. De acordo com o PDRAE, a esfera privada passa a atuar não como um mero colaborador do Estado, mas como um verdadeiro substituto do ente estatal, no campo de atuação dos direitos sociais e, dentre eles, a educação, com consequências para a gestão democrática. É com a edição do PDRAE que ocorria a redefinição do papel do Estado, que deixava de ser o responsável pela promoção das políticas sociais, tornando-se apenas o regulador desse desenvolvimento. A educação, quando 
é vista unicamente sob a perspectiva do público não estatal, transforma-se gradativamente em um serviço, exigindo tão somente que sua prestação ocorra de forma eficiente, visando apenas à produção de resultados. Por se tratar de um serviço, ou, ainda, de um bem de consumo, deve atender às necessidades do mercado. Ao contrário do que se possa pensar, a relação público-privada não permitiu que a totalidade da sociedade civil passasse a ser detentora do conhecimento disputado dentro da ordem capitalista. $\bigcirc$ que prevaleceu é que a sociedade civil, no atual contexto de crise econômica, acabou se responsabilizando pelas políticas sociais. A sociedade passou a vincular-se às organizações do Terceiro Setor, legalmente reconhecidas, e a firmar parcerias com o poder público, agindo no cumprimento das obrigações que o Estado deixava de executar (PIRES, 2009). Para Bruno (2002, p. 27):

[...] falam e procuram justificar a redução dos investimentos estatais nas políticas sociais, transferindo parte da responsabilidade sobre esses serviços para a própria classe trabalhadora, que além de sua jornada de trabalho diária (quando a tem), deve também assumir uma segunda, durante a qual haverá de produzir para si mesma aquilo que o Estado se desobrigou de fornecer-lhe. Outra parte desses serviços é transferida para o setor privado, onde estes são produzidos como mercadoria, operando-se assim a expansão do mercado de bens e serviços consumidos pela classe trabalhadora. Esse processo é bastante visível no caso da educação.

A educação, quando promovida essencialmente por interesses particulares, faz com que os cidadãos não participem do controle dos bens produzidos em sociedade, dentre eles o próprio conhecimento. Quem acaba controlando é uma pequena parcela da sociedade ou o mercado, quando a sua execução é transferida para o setor privado, evidenciando, no interior das escolas públicas, o estímulo a valores como a competitividade, a concorrência, o distanciamento dos princípios da gestão democrática, a premiação por desempenho, a ênfase nos resultados e a diminuição da autonomia dos professores. $\bigcirc$ acréscimo de eficiência na educação é um dos principais argumentos defendidos para a mudança na esfera de atuação das políticas 
educacionais, uma vez que a esfera privada é considerada "mais eficiente" que a esfera pública. De acordo com Arelaro (2007, p. 916):

Adotando estas políticas na área educacional, onde a prestação da baixa qualidade da educação pública oferecida justifica a tese de que a adoção destas "estratégias" - ainda que aparentemente provisórias colaborariam (pois elas são "parceiras") para tornar mais eficientes o trabalho educativo e os projetos das escolas, certamente a gestão democrática, com participação popular sempre crescente e suas intermináveis discussões, reuniões, sugestões e cobranças, é empecilho a ser superado, por desnecessário.

Para os que defendem a adoção da relação público-privada nas escolas públicas, entende-se que a gestão democrática se torna um empecilho na busca por resultados mais eficientes. Não podemos esquecer que a gestão democrática é uma conquista constitucional, pois somente a partir da CF de 1988 a gestão democrática do ensino foi erigida à categoria de princípio constitucional, após a correlação de forças do período que antecedeu a promulgação da Carta de 1988.

Diversas entidades nasceram neste período da luta contra a ditadura expressando esta correlação de forças. Entre elas, destacam-se as propostas feitas durante a IV Conferência Brasileira de Educação (CBE), em 1986, na qual foram debatidas propostas a serem incorporadas na Constituição Nacional. $\bigcirc$ documento resultante daí foi a "Carta de Goiânia", que incluía mecanismos de democratização da gestão da educação, como, por exemplo, a educação entendida como direito de todos, sendo gratuita e laica nos estabelecimentos públicos; ensino fundamental obrigatório, com duração de oito anos; garantia do Estado à sociedade civil do controle e execução da política educacional por colegiados constituídos democraticamente; participação e mecanismos de controle social efetivo assegurados pelo Estado. Outro movimento importante foi o Fórum de Educação na Constituinte em Defesa do Ensino Público e Gratuito (mais tarde passou a chamar-se de Fórum Nacional em Defesa da Escola Pública - FNDEP, que atuou na constituinte e na elaboração da Lei de Diretrizes e Bases - LDB). Seu lançamento ocorreu por meio da "Campanha Nacional pela Escola Pública e Gratuita" e acompanhado pelo "Manifesto em Defesa da Escola Pública e Gratuita". $\bigcirc$ 
Fórum surgiu como um espaço para debater a construção de um projeto para a educação como um todo e não somente para a escola, lutando pela redemocratização da educação e objetivando a elaboração de uma carta magna para o país. (LUMERTZ, 2007, p. 38).

Entre os mecanismos de gestão democrática estão a participação de todos os sujeitos envolvidos no processo escolar, como professores, alunos, funcionários e pais nos processos de tomada de decisões da escola; entretanto, tal conquista acaba por significar uma dificuldade quando se buscam exclusivamente resultados educacionais. Em que medida o princípio da gestão democrática do ensino passou a significar um problema para a educação? Qual o objetivo de uma educação que se pretende eficiente e que não leva em consideração os princípios democráticos da escola? Para os teóricos da Terceira Via, por exemplo, a participação é defendida, porém, com outro sentido. Significa, em sua essência, que a sociedade civil, quando exerce seu direito de participação, o faz na medida em que assume a responsabilidade pela execução das políticas sociais. Esse é o entendimento de Bezerra (2008, p. 47-48):

$\bigcirc$ discurso da gestão democrática e participativa que emerge no âmbito da reforma do Estado, iniciada nos anos 1990, enfatizando a participação da sociedade civil, se apresenta inseparável das estratégias de transferência da responsabilidade para as populações beneficiárias dos serviços públicos. Assim, a política de descentralização, democratização das escolhas dos dirigentes e participação das organizações e lideranças nos núcleos gestores articula medidas como a otimização dos recursos, a flexibilização dos direitos, o autofinanciamento das instituições e a privatização com a co-responsabilização das populações na aplicação destes planos.

A "participação" da sociedade nos sistemas de ensino público significa a transformação gradativa do direito à educação em um bem de consumo, deixando de ser um direito e uma conquista de todos os cidadãos. A base ideológica na qual se baseiam os partidários que defendem o estímulo às parcerias entre os setores públicos e privados é justificada, de acordo com Bruno (2002, p. 26), da seguinte maneira: 
Trata-se de justificar o crescente descompromisso do estado quanto ao financiamento e à implementação das políticas sociais compensatórias, cujo alvo é a classe trabalhadora, e, ao mesmo tempo e até bem mais importante, expressa a extensa reorganização do poder hoje, que se desloca do aparelho central do estado nacional para uma multiplicidade de centros estreitamente inter-relacionados.

Para a autora, esse novo rearranjo na estrutura estatal, ou a nova configuração da organização estatal, caracteriza-se pela inserção de novos sujeitos na execução de várias funções dentro da esfera de responsabilidade estatal. Nesse contexto, incluem-se as novas formas de atuação do Estado no campo educacional, entre elas, a descentralização, a privatização, a focalização e a terceirização, como consequência da forte influência da ideologia neoliberal, destacada pela autora. $\bigcirc$ que se constata é uma alteração na relação entre o Estado e a sociedade, que vai mudar significativamente a lógica dentro dos sistemas escolares. Nesse sentido, a escola se vê diante de uma lógica que não privilegia o ideário democrático do ensino, mas a lógica de mercado e da competição, tendo como resultado a mercantilização dos sistemas de ensino. Desse modo, de acordo com Brito (1995, p. 136),

As lutas pela democratização da sociedade brasileira, os
movimentos em prol da educação pública, a organização
do setor da saúde, os movimentos sociais vão expressar
uma negação da identificação da relação público-estatal
e reivindicar um conjunto de políticas sociais, articuladas
com a inserção dos brasileiros na sociedade, enquanto
portadores de direito.

Para tanto, quando se faz referência à educação, trata-se de um direito, uma conquista e uma garantia constitucional, que enseja a obrigação do ente estatal, pois estamos tratando de um direito assegurado a todos os cidadãos, não podendo ser visto com uma mera concessão ou um serviço que é prestado a um cliente. Ainda sobre a gestão da escola, Laval (2004, p. 3) faz referência ao fato de que 
[...] o novo modelo escolar e educativo que tende a se impor está fundamentado, inicialmente, na sujeição mais direta da escola à razão econômica. Ele depende de um "economizou", aparentemente simplista cujo axioma principal é que as instituições, em geral, e as escolas, em particular, só têm sentido dentro do serviço que elas devem prestar às empresas e à economia.

Quanto às políticas educacionais, sendo esta uma política social de responsabilidade exclusiva do Estado, analisada a partir de categorias restritas do pensamento neoliberal, vinculam-se à crise pela qual passam os sistemas de ensino no que tange à atuação exclusiva da esfera pública. Dessa forma, a solução pensada pelos teóricos do Neoliberalismo é orientar a política educacional a partir dos preceitos que dirigem os mercados, ou seja, para o setor privado (PIRES, 2009).

Na democracia liberal, portanto a política social toma como alvo a igualdade de cidadania para homens pertencentes à sociedade orientada pelo mercado e caracterizada pela desigualdade econômica. Por isto, a política econômica está atrelada à política social, mas se colocando normalmente acima desta. Os direitos sociais integrantes da cidadania podem mitigar a desigualdade dos homens e até contribuir à mudança nas condições de produção, não abolindo a situação desproporcional estabelecida entre os poucos possuidores de capital e os muitos vendedores da força de trabalho. (VIEIRA, 1992, p. 97).

O direito à educação enseja a correlata obrigação do Estado em prestá-la, isto é, um dever, que importa na necessária observância dos princípios que orientam a atividade estatal, quer sejam expressas, como a legalidade e a impessoalidade, quer sejam implícitas, como o princípio da continuidade dos serviços públicos. A educação, como um direito de todos, conforme está disposta de forma expressa no art. 205 da Carta Magna de 1988, estabelece que o Estado seja o titular na promoção da educação. Conforme disposto nesse artigo: "Art. 205. A educação, direito de todos e dever do Estado e da família, será promovida e incentivada com a colaboração da sociedade, visando ao pleno desenvolvimento da pessoa, seu preparo para o exercício da cidadania e sua qualificação para o trabalho." Entretanto, percebe-se que a influência 
da elite dirigente no Brasil é determinante, na medida em que nem a CF de 1988 é resguardada, evidenciando, de acordo com Leão (2003), uma postura "pseudodemocrática". Ademais, segundo o autor,

A ampliação do poder privado nas escolas, seja por meio da exploração direta do mercado educacional, seja por meio da imposição de uma lógica administrativa que legitima os interesses do capital. Estamos no seio de uma complexidade em que o capital adquire novos contornos e legitima a sua interpretação sobre a crise educacional, aliando discurso conservador e soluções pseudodemocráticas. (LEÃO, 2003, p. 121).

É necessário, no caso da educação, pensá-la na qualidade de uma autêntica política social, de natureza pública, o que significa, em linhas gerais, vislumbrar a premissa do poder estatal em ação, comprometido em estimular políticas sociais públicas que garantam o acesso, a qualidade e a permanência dos educandos nos sistemas de ensino, o que equivale a afirmar: a sua democratização. Portanto, é fundamental entender como a política educacional está se materializando nesse momento particular de crise do capitalismo, sendo necessária uma reflexão acerca das transformações sociais e políticas que o nosso País e a educação atravessaram ao longo do seu processo histórico, tendo por base a gradativa "desresponsabilização" da esfera pública em promover a efetividade dos direitos sociais, em especial a educação, e a necessidade de fortalecer a democracia como um valor e um fundamento do Estado brasileiro.

\section{CONSIDERAÇÕES FINAIS}

Em 01 de abril de 1964 foi deflagrado o Golpe Civil-Militar, que perdurou por 21 anos, uma das mais longas ditaduras da América Latina, provocando inúmeras violações aos direitos humanos e às garantias fundamentais, suprimindo, dessa maneira, conquistas individuais e coletivas. Em termos educacionais, esse período foi o de maior impulso à privatização da educação. $\bigcirc$ estágio econômico experimentado pelo País naquele momento 
beneficiou a burguesia industrial e o capital financeiro. Nessa senda, a educação, conforme analisamos, deveria contemplar dois requisitos: tornar-se uma atividade de base lucrativa e realizar o controle ideológico da população. $\bigcirc$ Governo centralizou o controle pela produção das diretrizes educacionais e promoveu a liberalização do seu fomento à iniciativa privada, respaldado no texto da Constituição de 1967 e na Emenda Constitucional n. 1 de 1969.

Já os anos 1980 marcaram o esgotamento do Estado de exceção e a luta dos movimentos sociais pela redemocratização pela educação pública, dos quais destacamos o Fórum Nacional em Defesa da Escola Pública. Todavia, nesse mesmo momento os Estados Unidos e a Inglaterra difundiam mundialmente a orientação neoliberal, na qual, dentre suas premissas, constam a privatização dos setores sociais e a não intervenção do Estado na economia. É nesse contexto que a Constituição Federal de 1988 foi promulgada. Ela consagrou, além da esfera do público e do privado, uma nova categoria, o confessional ou filantrópico, que significava a ação particular, mas com um sentido público, o chamado público não estatal. As entidades públicas não estatais foram amplamente estimuladas a partir dos anos 1990, com o advento das parcerias público-privadas entre o Estado e as entidades do Terceiro Setor, que se qualificaram juridicamente como entidades de direito privado sem fins lucrativos. Nesse aspecto residiu uma das maiores inquietações do estudo, pois quando o Estado se aproximava da titularidade da promoção da educação pública em uma perspectiva democrática, admitindo a sua função e empenhando esforços para executá-la, as forças sociais privatizantes se organizavam para deslegitimar essas pretensões. A valorização das entidades do Terceiro Setor é parte da consolidação de uma orientação política que surge na Inglaterra, definida como Terceira Via, estruturada por Giddens (1999), que se coloca como uma alternativa à antiga socialdemocracia e ao neoliberalismo. Entre as suas características estão o estímulo ao voluntariado, a desresponsabilização na execução direta das políticas sociais pelo poder público - repassando para a sociedade civil - e o incentivo à meritocracia. Para Giddens (1999), é necessário "democratizar a democracia." A estratégia é justificar a desobrigação estatal com um discurso envolvente, o qual a sociedade civil acabou legitimando ao assumir a execução das políticas sociais. 
Isso fortalece indiretamente o empresariado na educação, com instituições bancárias, grandes conglomerados empresariais e setores da mídia, que passam a identificar possibilidades bastante rentáveis quando assumem funções estatais em relação aos direitos sociais, sendo essa atitude estimulada pelo Estado por meio de incentivos fiscais e financeiros.

A educação é consequência do movimento histórico, sendo parte constitutiva de um Estado Democrático de Direito em construção e que não atingiu a sua real plenitude, não podendo ser analisada, portanto, sem a intermediação dos fatores políticos e econômicos. Tais constatações nos induzem à seguinte conclusão: enquanto não vencermos a lógica histórica de apropriação dos espaços de decisão pública por setores privados hegemônicos, a democratização da escola e dos processos educacionais não conseguirá se consolidar conforme estabelece a Carta Política de 1988.

Essa relação reflete a noção do público no Estado brasileiro como um espaço privilegiado para a manutenção dos privilégios privados e do status quo. Somente conseguiremos ultrapassar o atual estágio histórico do nosso desenvolvimento com a ruptura da ordem vigente que historicamente se estruturou. Uma alteração nessa conjuntura somente acontecerá por intermédio de uma maior conscientização e organização da coletividade, que deverá exercer o seu papel, não assumindo funções estatais, mas fornecendo a pauta para a elaboração das políticas públicas educacionais, que deverá primar pelo todo e não apenas para uma parte historicamente privilegiada, acrescido da necessidade de valorizarmos a matriz e o fundamento do Estado de direito brasileiro, impulsionando, dessa forma, para a verdadeira democracia.

\section{REFERÊNCIAS}

ARELARO, L. R. G. Formulação e implementação das políticas públicas em educação e as parcerias público-privadas: impasse democrático ou mistificação política? Educação e Sociedade, Campinas, v. 28, n. 100, p. 899-919, 2007. 
BEZERRA, J. E. B. Crise: Reforma do Estado e Gestão da Educação: $\bigcirc$ que dizem as diretrizes das Instituições Multilaterais? In: ALBUQUERQUE, G. M. T.; FARIAS, I. M. S.; RAMOS, J. F. P. (Org.). Política e Gestão Educacional. Contextos e Práticas. Fortaleza: Ed. UECE, 2008. p. 43-65.

BIANCHETTI, R. G. Modelo Neoliberal e Políticas Educacionais. São Paulo: Cortez, 1999.

BRASIL. Constituição da República Federativa do Brasil: outorgada em 24 de janeiro de 1967. Brasília, DF: Senado Federal, 1967.

\section{BRITO, V. L. F. A. O Público e o Privado e a Lei de Diretrizes e Bases da} Educação Nacional. 1995. Tese (Doutorado em Educação)-Faculdade de Educação, Universidade Federal de Minas Gerais, Belo Horizonte, 1995.

BRUNO, L. Gestão da Educação: Onde Procurar o Democrático? In: OLIVEIRA, D. A.; ROSAR, M. F. F. (Org.). Política e Gestão da Educação. Belo Horizonte: Autêntica, 2002. p. 84-100.

CUNHA, L. A. Educação, Estado e Democracia no Brasil. 6. ed. São Paulo: Cortez, 2009.

FERNANDES, F. A Revolução Burguesa no Brasil. São Paulo: Globo, 2005.

GERMANO, J. W. Estado Militar e Educação no Brasil (1964-1985). 2. ed. São Paulo: Cortez, 1994.

GIDDENS, A. A Terceira Via. Reflexões sobre o Impasse Político Atual e o Futuro da Socialdemocracia. Rio de Janeiro: Record, 1999.

HARVEY, D. A Condição Pós-Moderna. São Paulo: Loyola, 1989.

LAVAL, C. A escola não é uma empresa. O neoliberalismo em ataque ao ensino público. Londrina: Planta, 2004.

LEÃO, G. M. P. "Novas" Estratégias da Gestão Privada da Educação Pública. In: OLIVEIRA, D. A.; DUARTE, M. R. T. (Org.). Política e Trabalho na Escola. Administração dos Sistemas Públicos de Educação Básica. Belo Horizonte: Autêntica, 2003. p. 32-51.

LUMERTZ, J. S. A Parceria Público-Privada na Educação: Implicações para a Gestão da Escola. 2007. Dissertação (Mestrado em Educação - Programa de Pós-Graduação em Educação, Faculdade de Educação)-Universidade Federal do Rio Grande do Sul, Porto Alegre, 2007. 
MORAES, R. Neoliberalismo. De onde vem, para onde vai? São Paulo: Senac, 2001 .

OLIVEIRA, R. P. de. Educação Pública e Privada na Constituição Federal de 1988. In: ADRIÃO, T.; PERONI, V. M. V. (Org.). O público e o privado na educação. Interfaces entre Estado e Sociedade. São Paulo: Xamã, 2005. p. 53-70.

PERONI, V. M. V. Política educacional e papel do Estado no Brasil dos anos 90. São Paulo: Xamã, 2003.

PERONI, V. M. V. As Implicações da relação público-privada para a democratização da educação no Brasil. 2016. Tese (promoção a Professor Titular da Carreira do Magistério Superior)-Universidade Federal do Rio Grande do Sul, Porto Alegre, 2016.

PIRES, D. O. A configuração jurídica e normativa da relação público-privada no Brasil na promoção do direito à educação. 2009. Dissertação (Mestrado em Educação - Programa de Pós-Graduação em Educação, Faculdade de Educação)-Universidade Federal do Rio Grande do Sul, Porto Alegre, 2009.

PIRES, D. O. A construção histórica da relação público-privada na promoção do direito à educação no Brasil. 2015. Tese (Doutorado em Educação - Programa de Pós-Graduação em Educação, Faculdade de Educação)-Universidade Federal do Rio Grande do Sul, Porto Alegre, 2015.

SANFELICE, J. L. Da escola estatal burguesa à escola democrática e popular: considerações historiográficas. In: LOMBARDI, J. C.; SAVIANI, D.; NASCIMENTO, M. I. M. (Org.). A Escola Pública no Brasil: História e historiografia. Campinas: Autores Associados, 2005. p. 71-93

VIEIRA, E. A Ditadura Militar: 1964-1985 (momentos da República brasileira). São Paulo: Cortez, 2014.

VIEIRA, E. Estado e Miséria no Brasil. De Getúlio a Geisel. São Paulo: Cortez, 1992.

Recebido em 30 de janeiro de 2018 Aceito em 08 de outubro de 2018

Endereços para correspondência: Avenida Diário de Notícias, 1555/1303, Torre 02, 90810-080, Bairro Cristal, Porto Alegre, Rio Grande do Sul, Brasil; danielaopires77@gmail.com 